Preliminary Pre-Shot Simulations of Far-Field Ground Motions for the Source Physics Experiment (SPE) Explosions at the Climax Stock, Nevada National Security Site

A. J. Rodgers, J. Wagoner, N. A. Petersson, B. Sjogreen

November 11, 2010 
This document was prepared as an account of work sponsored by an agency of the United States government. Neither the United States government nor Lawrence Livermore National Security, LLC, nor any of their employees makes any warranty, expressed or implied, or assumes any legal liability or responsibility for the accuracy, completeness, or usefulness of any information, apparatus, product, or process disclosed, or represents that its use would not infringe privately owned rights. Reference herein to any specific commercial product, process, or service by trade name, trademark, manufacturer, or otherwise does not necessarily constitute or imply its endorsement, recommendation, or favoring by the United States government or Lawrence Livermore National Security, LLC. The views and opinions of authors expressed herein do not necessarily state or reflect those of the United States government or Lawrence Livermore National Security, LLC, and shall not be used for advertising or product endorsement purposes.

This work performed under the auspices of the U.S. Department of Energy by Lawrence Livermore National Laboratory under Contract DE-AC52-07NA27344. 


\title{
Pre-Shot Simulations of Far-Field Ground Motions for the Source Physics Experiment (SPE) Explosions at the Climax Stock, Nevada National Security Site
}

\author{
Arthur J. Rodgers, Jeffrey Wagoner, N. Anders Petersson and Bjorn Sjogreen \\ Geophysical Monitoring Program \\ Global Security Principle Directorate \\ Lawrence Livermore National Laboratory \\ Livermore, CA 94551
}

\section{Summary}

The Source Physics Experiment (SPE) will involve a series of explosions in various geologic and emplacement conditions to validate numerical simulation methods to predict behavior of seismic wave excitation and propagation for nuclear test monitoring. The first SPE's currently underway involve explosions in the Climax Stock (granitic geology) at the Nevada National Security Site (NNSS). Detailed geologic data and published material properties for the major lithologic units of the NNSS and surrounding region were used to build three-dimensional models for seismic wave propagation simulations. The geologic structure near the SPE shot point is quite varied including granitic, carbonate, tuff and alluvium lithologies. We performed preliminary ground motion simulations for a near-source domain covering $8 \mathrm{~km}$ x $8 \mathrm{~km}$ at the surface centered on the shot point to investigate various source and propagation effects using WPP, LLNL's anelastic seismic wave finite difference code. Simulations indicate that variations in wave propagation properties of the sub-surface will generate strongly path-dependent response once the energy has left the relatively small granitic geology of the near-surface Climax Stock near the SPE shot point. Rough topography to the north and west of SPE shot point causes additional complexity in the signals including energy on the transverse components. Waves propagate much faster through the granitic and carbonate formations and slower through the tuff and alluvium. Synthetic seismograms for a pure explosion 
source in a 3D geologic structure show large amplitudes on transverse component. For paths to the south sampling the granite, tuff and alluvium lithologies transverse component amplitudes are as high as $50 \%$ of that on the vertical and radial components.

\section{Introduction}

The Source Physics Experiment (SPE) is a major new research effort to improve understanding and predictive modeling capabilities for the generation and propagation of seismic waves from explosions for nuclear explosion monitoring. Explosions will be conducted at the Nevada National Security Site (NNSS). The SPE will involve explosions in different emplacement conditions such as different lithologies (rock types), depth-for-burial, yield and near-source rock conditions. The objective of the SPE is to develop predictive capabilities of explosion generated seismic and acoustic waves using numerical simulation. This builds on the national laboratories existing capabilities for numerical simulation of explosion phenomena and world class high performance computing. The first SPE explosions will be conducted in the Climax Stock, a granitic body just north of Yucca Flat.

This report will describe preliminary efforts at Lawrence Livermore National Laboratory (LLNL) to simulate the far-field (elastic) motions generated by the first planned SPE explosions before the explosions take place. The goal of this report is to demonstrate the current far-field seismic wave modeling capabilities and to make predictions of the motions with the current understanding of the geology and seismic wave propagation properties of the NNSS unbiased by the actual recordings of the motions. By far-field we refer to the region beyond the non-linear/linear transition near the explosion, or the socalled elastic transition. Admittedly far-field spans a large range of distances from a few meters away from the shot point (ground zero, GZ) to the most distant recordings. Because the geologic structure varies so much at the NNSS the motions are strongly impacted for distances of less than 1 kilometer $(\mathrm{km})$. Another report on simulation of the near-field region with non-linear hydrodynamic modeling is underway. 


\section{The SPE Seismic Network}

A dedicated network of near-field accelerometers, seismic and infrasound sensors will record all explosion wave motions. Seismic stations will cover the near field to nearregional distances $(\sim 100 \mathrm{~km}$ although signal strength will strongly depend on explosion yield and emplacement conditions). Figure 1 shoes the seismic stations that will record the first SPE shots, displayed on regional and local scales.
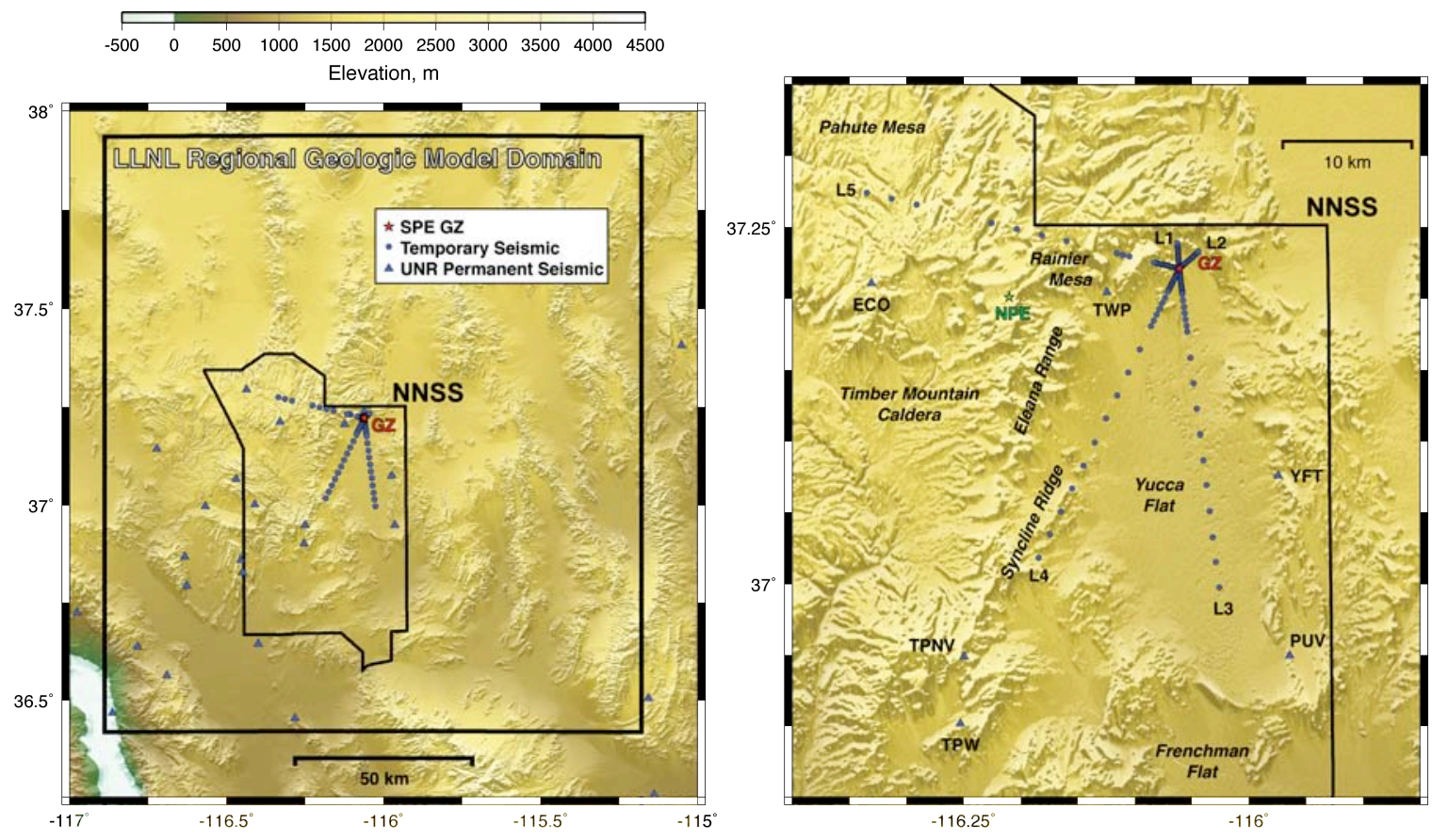

Figure 1. Map showing permanent (triangles) and temporary (circles) seismic stations that will record the first round of SPE shots along with topography. SPE ground zero is indicated by the red star. (left) Regional scale covering southern Nevada and the boundary of the Nevada National Security Site (NNSS). (right) Local scale covering the northern part of the NNSS. Note that the Non-Proliferation Experiment (NPE) ground zero is shown with a green start.

The permanent seismic network operated by the University of Nevada at Reno (UNR) will record the shots including stations within $10 \mathrm{~km}$ (TWP) and others at larger distances. A dedicated network of temporary seismic stations has been deployed by Sandia National Laboratory (SNL) and National Security Technologies (NSTec) to record the shots. These stations are deployed in five lines radially outward from the GZ at different azimuths with dense spacing of $100 \mathrm{~m}$ within $2 \mathrm{~km}$ of GZ, $500 \mathrm{~m}$ from 2-5 $\mathrm{km}$ and $2 \mathrm{~km}$ spacing beyond. Two lines are quite short (L1 and L2) due to rough 
topography and proximity to the NNSS boundary. Additional seismic stations will be deployed, including rotational sensors. The exact configuration of stations will not be known until the actual experiment take place.

\section{Geologic and Geophysical Properties of the SPE and NNSS}

Seismic waves are strongly impacted by geologic structure of the earth that manifests itself as three-dimensional (3D) variations in density and compressional and shear wavespeeds. This leads to strong source-sensor path variations in the ground motions. Surface topography also impacts ground motions especially for sources near the surface such as shallow explosions and where topography is rough. There exists a tremendous wealth of geologic and geophysical data for the NNSS based on characterization and well-logs studies done during the era of underground nuclear testing. These data exist in the legacy archives of the Nuclear Test and Containment Programs at the nuclear laboratories. LLNL has integrated much of these data into a unified database for the purposes of generating detailed 3D models for geophysical studies, including explosion containment, hydrodynamic, seismic ground motion and hydrologic investigations. For some projects, such as seismic ground motion modeling, it is necessary to include regions off the NNSS where distant observations may be made.

Geologic characterization involves the specification of the contact surfaces between major lithologic (rock type) units that have different geophysical properties (such as density, seismic wavespeeds, porosity, permeability, etc...). Figure 2 shows the geology at the surface for a large region spanning approximately $170 \mathrm{~km}$ in the north-south and $150 \mathrm{~km}$ east-west directions. The geology of southern Nevada is dominated by basin and range style tectonics. Basins are filled with sedimentary deposits and flat topography, while ranges have higher elevations and are composed of harder Tertiary (volcanic tuff) and pre-Tertiary (Paleozoic) rocks. For a summary of geologic structure of the NNSS see Howard (1985). The main geologic units are:

- Alluvium - sedimentary deposits

- Tertiary - volcanic tuff and ash 
- Pre-Teriarty - carbonate rocks, such as limestones and dolomites

- Intrusives - igneous, plutonic rocks such as granite and granodiorites

- Caldera - ash flows and debris filling inactive volcanic calderas

The lithologic units exposed at the surface are indicated in Figure 2. Also indicated are the Climax Stock and the familiar testing areas: Yucca Flat (YF); Rainier Mesa (RM) and Pahute Mesa (PM).

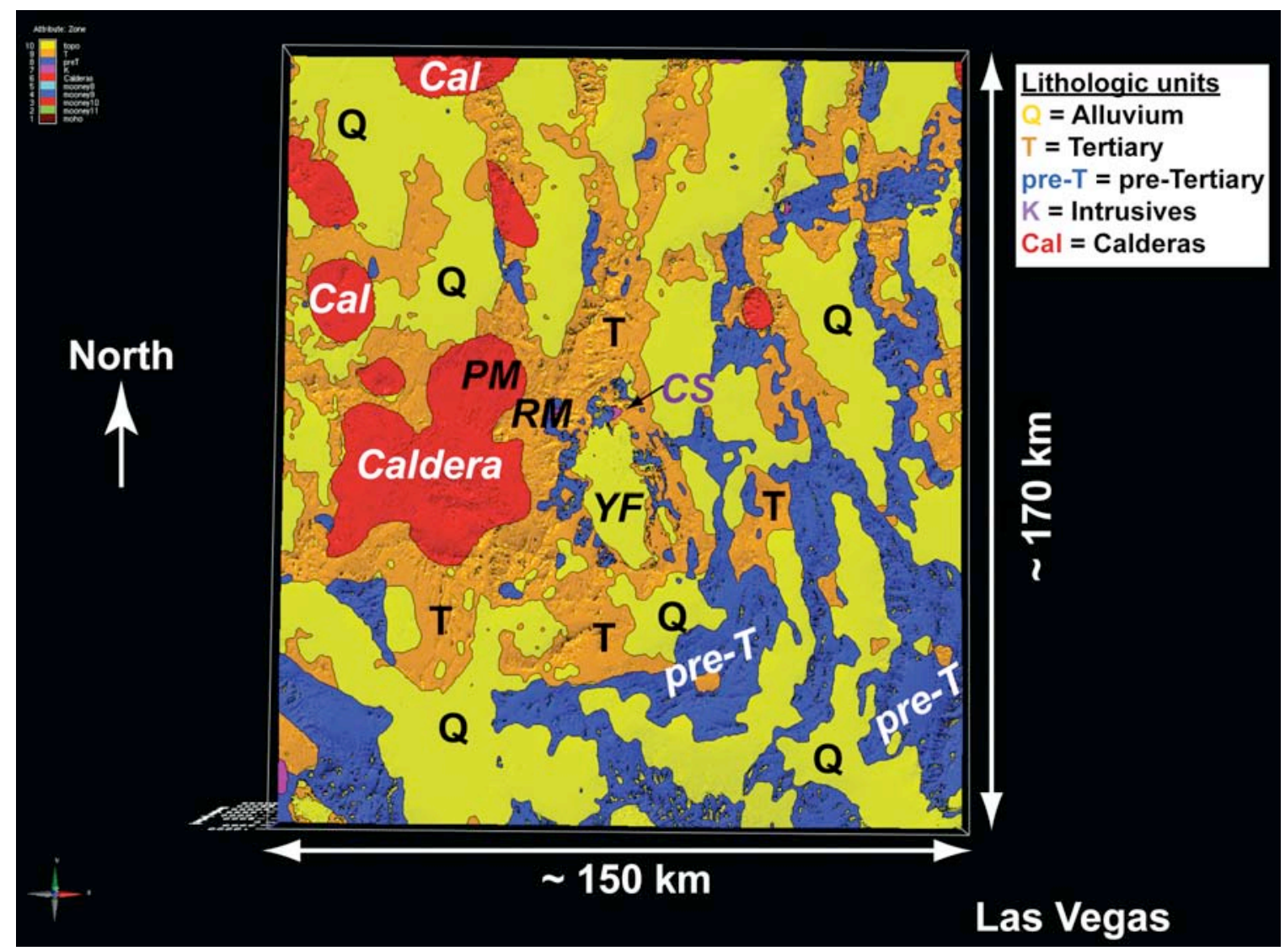

Figure 2. Surface geology for a large region centered near the SPE shot point spanning approximately $150 \mathrm{~km}$ by $170 \mathrm{~km}$. The lithologic units are color-coded and indicated in the key. Geographic features on the Nevada National Security Site are indicated: CS = Climax Stock; YF = Yucca Flat, RM = Rainier Mesa; and PM = Pahute Mesa.

The Climax Stock is a massive intrusive granitic body that has only a small exposure at the surface in the northern margin of Yucca Flat and parts of Rainier Mesa. The lateral extent of this body is inferred from gravity and other geophysical data. Figure 3a shows 
the Climax Stock body in 3D with overlaying lithologic units removed. The entire 3D geologic structure covering the Climax Stock, the northern part of Yucca Flat and Rainier Mesa is shown in Figure 3b. Topography is quite flat in Yucca Flat but hills rise steeply toward Rainier Mesa to the west and north of the surface exposure of the Climax Stock.
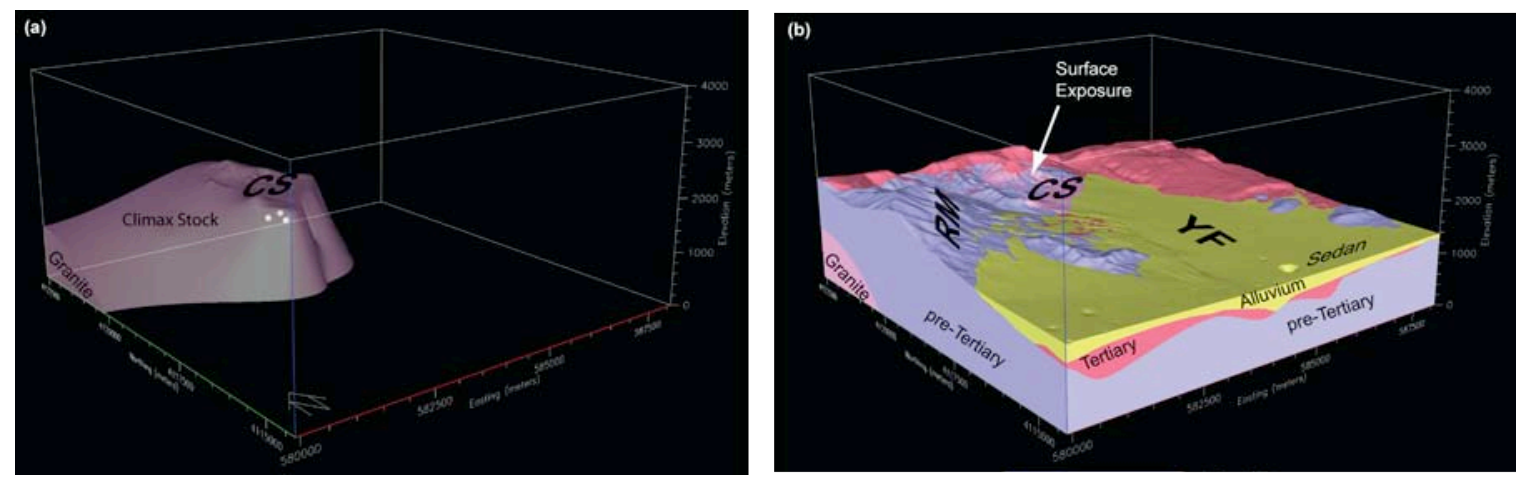

Figure 3. 3D geology and topography near the SPE shot-point showing (a) the Climax Stock (CS) granitic body and (b) major lithologic units, RM=Rainier Mesa and $\mathrm{YF}=$ Yucca Flat.

Geologic data from a wide variety of sources are integrated at LLNL using the EarthVision software developed by Dynamic Graphics Inc. Surfaces are output for use in our seismic wave simulations. While the depth to each lithologic unit is specified by the geologic model, seismic simulations require material properties for wave propagation, specifically the density, $\rho$, compressional and shear wavespeed, $v_{P}$ and $v_{S}$, respectively. The material properties are known to vary greatly for the range of lithologies considered at the NNSS. Summaries of material properties are compiled in reports published by Nuclear Test and Containment Programs at the nuclear laboratories (e.g. Howard, 1985).

For this study we performed simulations for a limited domain around the SPE, $8 \mathrm{~km}$ by 8 $\mathrm{km}$ at the surface and $5 \mathrm{~km}$ in depth. Figure 4 shows the computational domain for our preliminary simulations, along with the topography and seismic stations. This domain allows us to simulate the response for the five seismic lines for ranges up to $4 \mathrm{~km}$ where the station spacing is quite dense and where the geologic structure varies dramatically (see below). We made simple assumptions and assigned constant seismic wave propagation properties for the lithologies in the NNSS model. The domain encompasses 
the four major lithologic units for the near-source SPE model. Table 1 gives the assumed constant material properties for the four lithologic units in the preliminary SPE model.

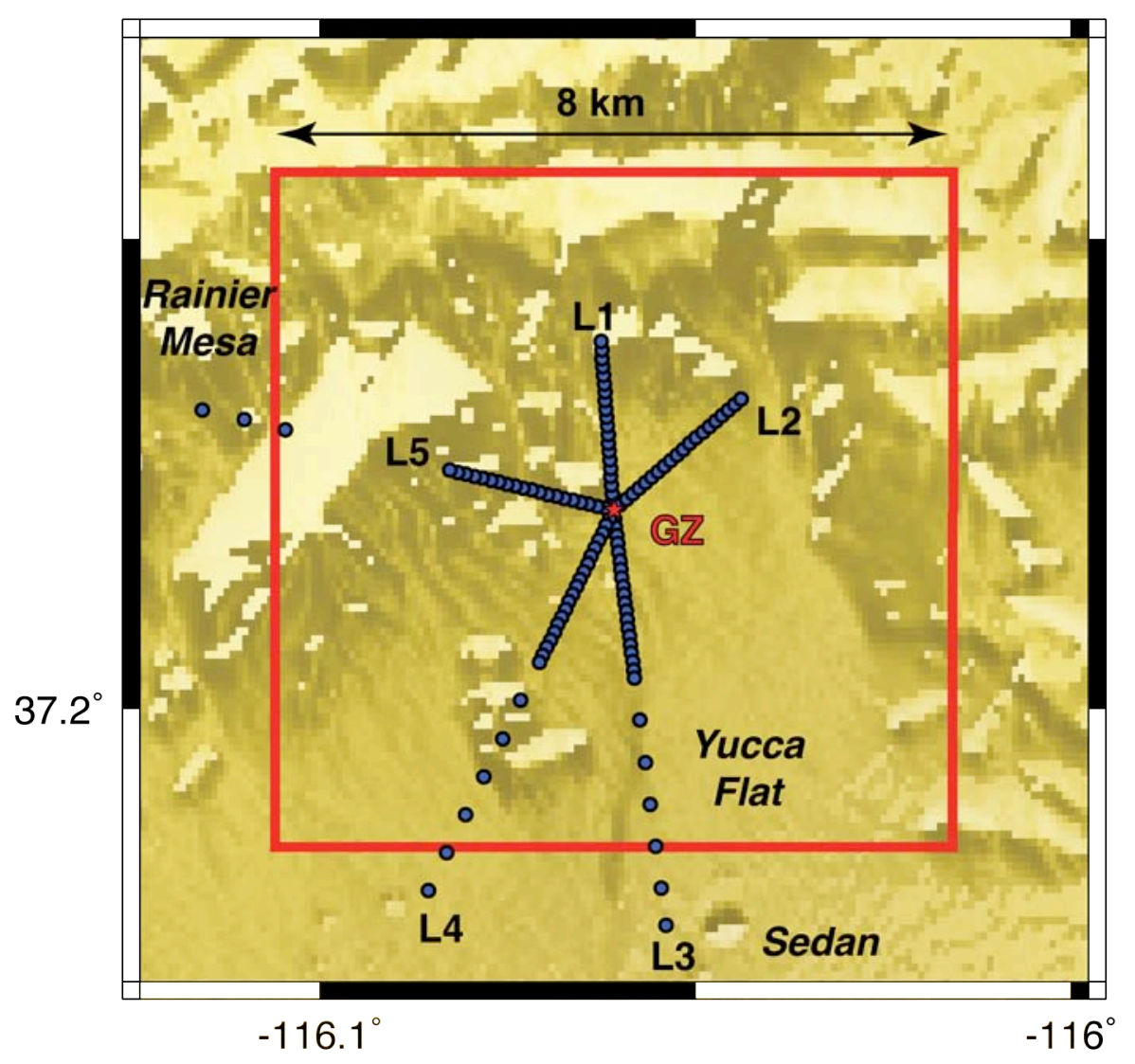

Figure 4. Computational domain for the preliminary ground motion simulations (red box) shown on a shaded relief plot. The SPE ground zero (GZ) shot point (red star) and seismic stations (blue circles) for the five seismic lines L1-L5 are indicated.

Table 1. Material properties of the four lithologic units in the near-source SPE model.

\begin{tabular}{|l|l|l|l|}
\hline Lithologic Unit & Density $\mathbf{( k g / \mathbf { m } ^ { 3 } )}$ & P wavespeed $\mathbf{( m / s )}$ & S wavespeed $\mathbf{( m / s )}$ \\
\hline Alluvium & 2000 & 1700 & 1000 \\
\hline Tertiary & 2100 & 2500 & 1445 \\
\hline Pre-Tertiary & 2300 & 4000 & 2312 \\
\hline Granite & 2600 & 5500 & 3179 \\
\hline
\end{tabular}

These material properties (Table 1) are assigned to the lithologic layers. The assumption of constant material properties is a rough approximation of the real earth. Even so there 
is considerable variation in estimates of the mean values of these material properties for the different lithologies. This is especially true for the alluvium and tuff lithologies.

Figure 5 shows the compressional (P-wave) wavespeed at the surface. Note that the Pwavespeed is plotted with shaded relief which changes the appearance but the material properties are constant. The geologic units are clearly delimited by the assumed lithologic properties and the contours indicate the boundaries between units.

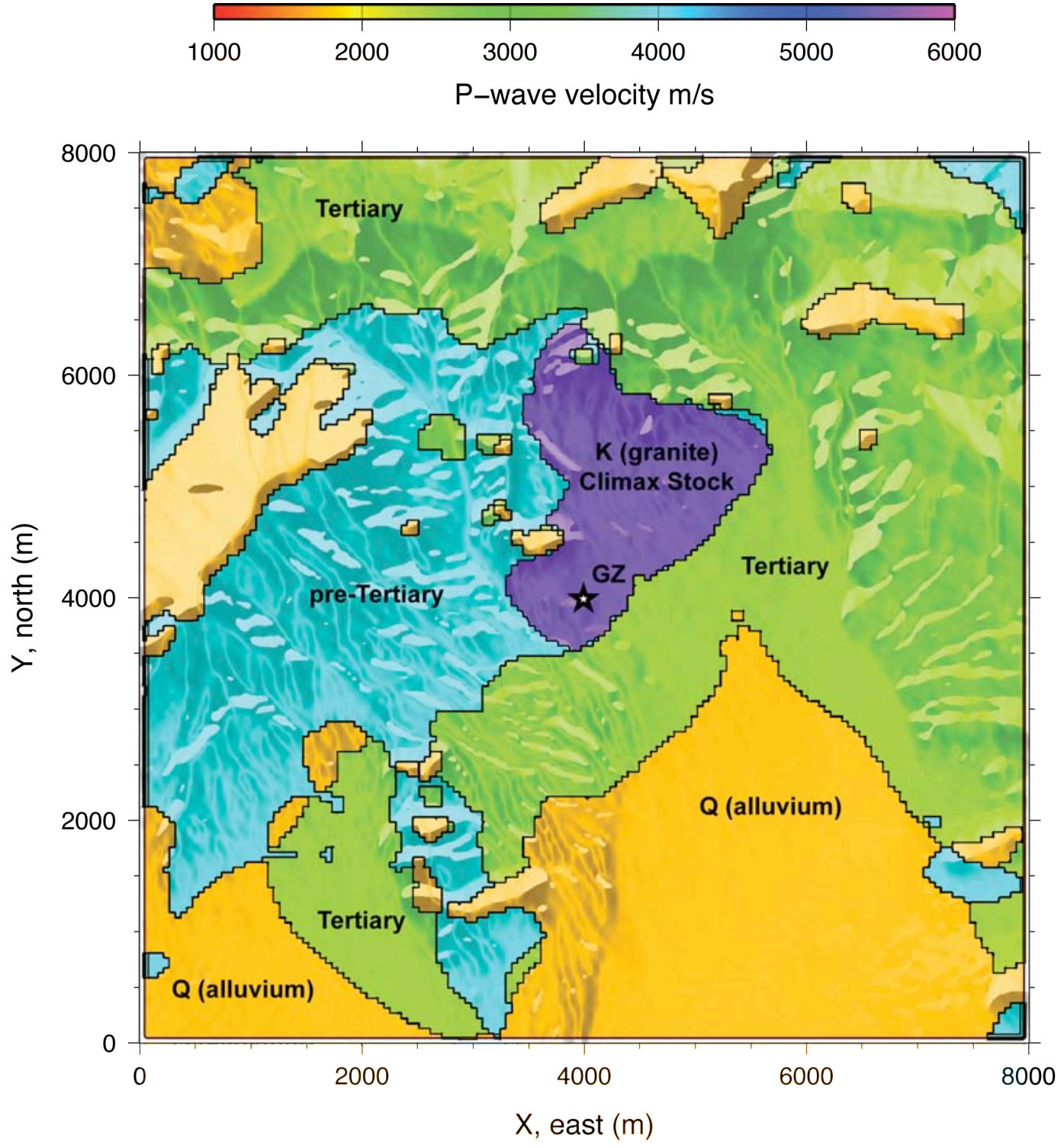

Figure 5. Map of compressional (P-wave) wavespeed at the surface based on the NNSS geologic model and assuming the simple constant material properties of each unit in Table 1. Note that the geology is shown along with shaded relief which distorts the color of the wavespeed regions. 
Note that the geologic units are separated by rectangular boundaries. This is an artifact of sampling the lithologic surfaces with relatively low resolution of 50 meters. This is a much coarser resolution than our grid spacing of 5 meters. In future simulations we will be able to render the model at much higher resolution and these artifacts will disappear. However, as will be seen the seismic wave simulations below this coarse version of the model does not strongly impact ground motions.

The variation in 3D structure is indicated in Figure 6 where we show the compressional wavespeed in depth cross-section through the SPE ground zero (GZ) along with the topography, which is included in our wave propagation modeling. Topography varies from approximately $1300-2200$ meters above sea level within the computational domain.
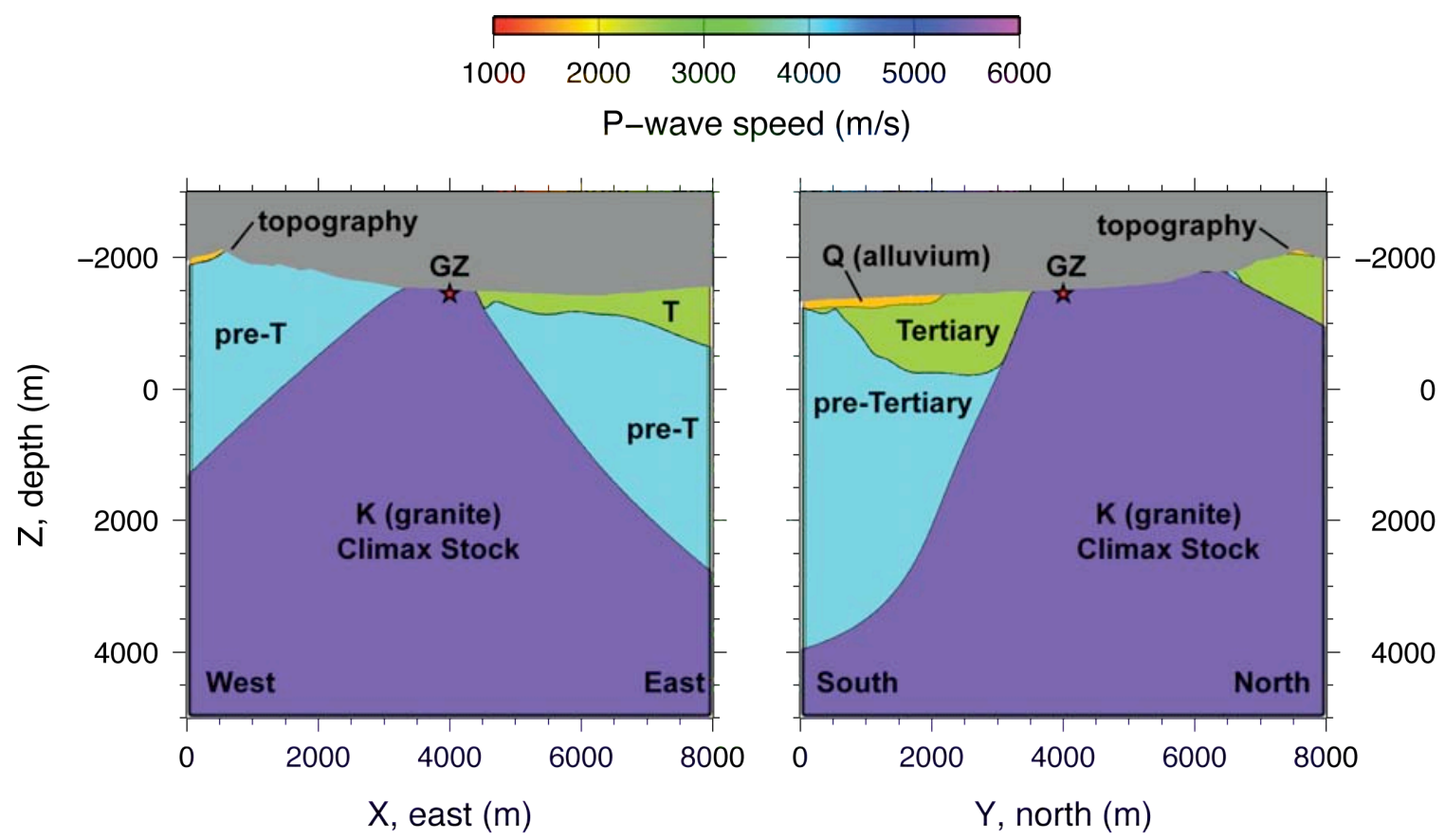

Figure 6. (left) West-to-east and (right) south-to-north vertical cross-sections of the compressional wavespeed through the preliminary SPE model, centered on ground zero (GZ). This model uses the surfaces specified by the NNSS model and constant material properties compiled in Table 1. 
We are able to assign more realistic depth-dependent properties to the lithologic units and will do this in later simulations. In fact variation in the material properties due to uncertainty leads to significant variation in the waveform response. These simulations should therefore be considered preliminary. Model validation using independent data from the SPE will be part of future studies.

\section{The WPP Anelastic Wave Propagation Code}

Simulations were performed using the WPP (Wave Propagation Program) computer code. This code is designed to model the ground motion response of the solid earth to explosion and earthquake forcing. It can run on single processors as well as massively parallel high performance computers, including Linux and IBM architectures. For most problems of interest high-performance computing is required to simulate the combination of large domain sizes, small grid spacing to resolve high-frequency waves and low nearsurface wavespeeds. WPP was designed with a number of features suited to simulate realistic three-dimensional (3D) modeling of seismic wave propagation. WPP includes the following features:

- $3 \mathrm{D}$ variations in the wave propagation properties (density, $\rho$, compressional and shear wavespeed, $v_{P}$ and $v_{S}$, respectively);

- $3 \mathrm{D}$ variations attenuation quality factors for compression and shear waves $\left(\mathrm{Q}_{\mathrm{P}}\right.$ and $\mathrm{Q}_{\mathrm{S}}$, respectively);

- lateral variations in the surface topography;

- general representation of seismic sources:

○ unlimited number of point sources

○ moment tensor (explosion, CLVD, double couple, etc...)

○ point forces;

- depth-dependent mesh refinement to allow coarser grid spacing for higher wavespeeds at depth;

WPP is an open source computer program. The source code, user reference guide and associated files can be obtained for free from the project website (Petersson, 2010). 
WPP uses a second-order node-centered (so called "full grid") finite difference scheme in Cartesian geometries. This method has several advantages over the conventional fourthorder velocity-stress staggered grid approach (Virieux, 1984, 1986; Levander, 1988; Graves, 1996). In particular, WPP solves the elastic wave equation as a second-order system of partial differential equations (PDEs) for the displacements without first rewriting the governing equations as a larger first-order system for the velocities and stresses. The most obvious advantage of our approach over the velocity-stress formulation is that the governing equations are a system of 3 PDEs instead of 9, thus reducing memory requirements. Furthermore, the current approach is stable for arbitrary heterogeneous elastic materials, thus removing the need to average any material properties, which often is necessary to prevent numerical instabilities in the velocitystress formulation. The difference formulae in our approach is more compact than the fourth order staggered grid scheme, and thus requires fewer memory accesses, which is becoming increasingly more important for good computational efficiency on modern high performance machines. However, these advantages are partially offset by the disadvantage that a second-order accurate method requires more spatial grid points per wavelength compared to a fourth-order method. All simulations presented in this study are based on at least 15 grid points per wavelength. The node-centered approach allows for the straight-forward application of a curvilinear mesh to represent surface topography and for the treatment of hanging nodes with mesh refinement.

WPP can accurately represent the free-surface boundary condition using a curvilinear grid. The code has a user-friendly feature to automatically build the mesh for the each simulation based on the grid spacing, mesh refinement and surface topography. WPP reads the input topography for the computational domain. Based on the wave propagation parameters the topography is filtered so that no short wavelength (high curvature) features in topography will introduce waves that cannot be resolved on the mesh. The curvilinear mesh is built using the filtered topography and merges with a standard Cartesian mesh at a user-specified depth. To illustrate this we show the input topography and the topography filtered by WPP in Figure 7. This figure shows that for 
the relatively fine grid with grid spacing, $\mathrm{h}=5$ meters, the topography used by WPP is undistinguishable from the actual topography.
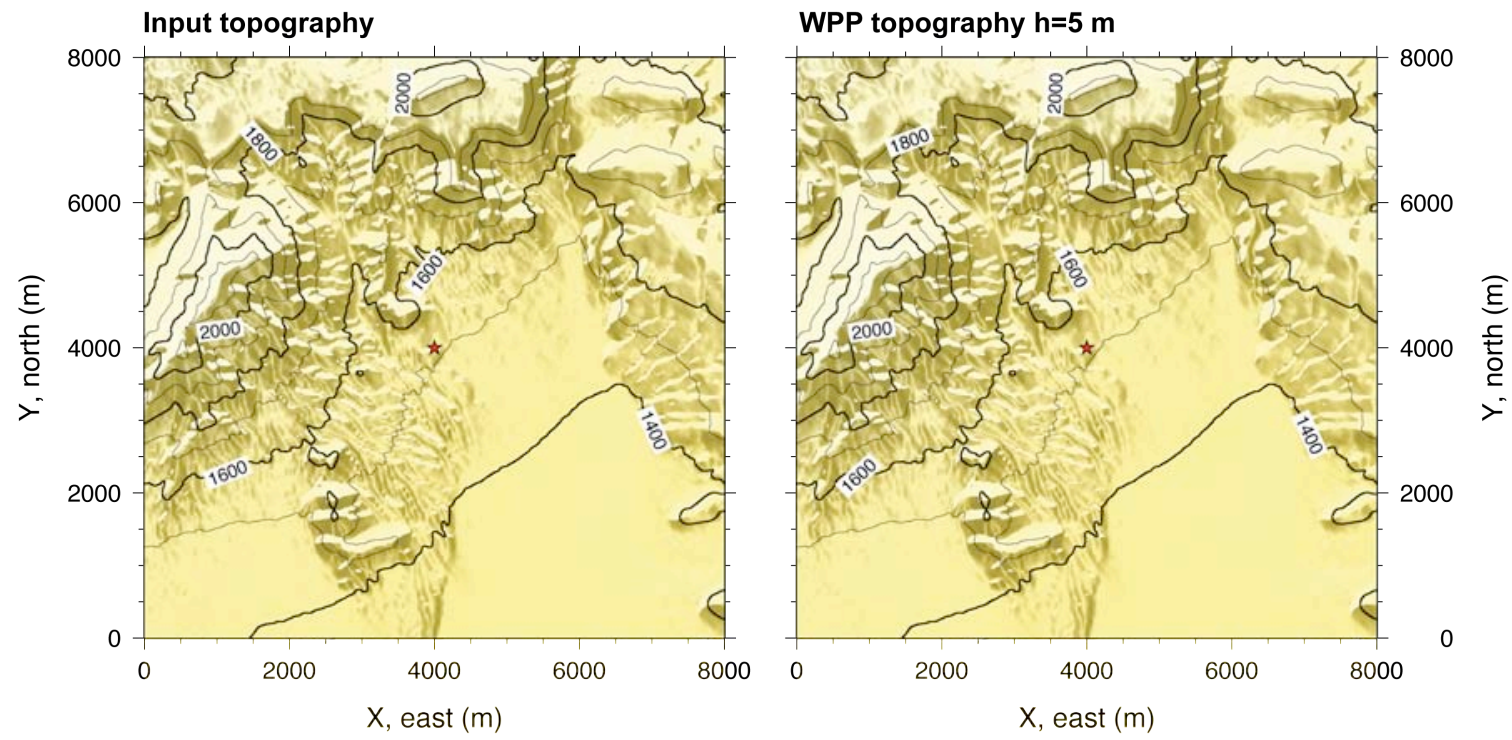

Figure 7. (left) Input topography for the SPE preliminary model domain and (right) topography after being read by $W P P$, filtered and used to create the curvilinear grid for the case when the grid spacing, $h=5$ meters.

Details on the WPP method can be found in various publications (Nilsson et al., 2007; Appelo and Petersson, 2008; Petersson and Sjogreen, Petersson and Sjogreen, 2010a). $W P P$ has been verified by several methods. We have compared the response from WPP calculations to analytic (e.g. Lamb's problem), semi-analytic and computed canonical solutions (e.g. layer over a half-space) to canonical problems, such as the Pacific Earthquake Engineering Research Center Lifelines Project tests of 3D elastodynamic codes (Day et al., 2001) and in models of three-dimensional heterogeneity by the method manufactured solutions (Nilsson et al., 2007). Validation of wave propagation with topography is demonstrated in (Appelo and Petersson, 2008). WPP has been used to model large $\left(\mathrm{M}_{\mathrm{W}}>6.5\right)$ finite rupture earthquakes such as the 1906 San Francisco earthquake (Aagaard et al., 2008), Hayward Fault scenario earthquakes (Aagaard et al., 2010) and to evaluate a 3D model of the San Francisco Bay Area (Rodgers et al., 2008). We have also used WPP to simulate the effects of realistic surface topography on shallow explosions such as the 2006 and 2008 North Korean nuclear tests (Rodgers et al., 2010).

\section{SPE Pre-Shot Simulations}


Pre-shot simulations for the planned SPE explosions seek to describe the elastic response using the current knowledge of the geology and material properties using simple representations of the source. Detailed non-linear modeling is also being done to estimate the response of SPE shots at the very-near source sensors. The objective of these simulations is to get a rough estimate of the explosion generated ground motions and obtain a baseline prediction of the ground motions unbiased by the actual data. We performed a series of simulations to investigate the effects of various features of the 3D seismic model. Several features of the simulations were common to all cases considered in this study:

- the same computational domain was used $8 \mathrm{~km} \times 8 \mathrm{~km} \times 5 \mathrm{~km}$;

- the grid spacing was 5 meters;

- the minimum wavespeed (shear wavespeed for alluvium) was $1000 \mathrm{~m}$;

- the combination of grid spacing, minimum wavespeed and resolution (points/wavelength) make it such that frequencies up to $13 \mathrm{~Hz}$ can be accurately resolved on the grid;

- the simulations included about 0.8 billion grid points, although the exact number of grid points is different for different cases;

- the same source location was used for each case;

Table 2. Some details of the preliminary far-field simulations.

\begin{tabular}{|l|l|l|l|l|l|}
\hline Run & Topography & Seismic Model & Source & $\begin{array}{l}\text { Depth } \\
(\mathbf{m})\end{array}$ & Effect investigated \\
\hline 1 & flat & $\begin{array}{l}\text { homogeneous } \\
\text { half-space }\end{array}$ & explosion & $60 \mathrm{~m}$ & baseline \\
\hline 2 & topo & $\begin{array}{l}\text { homogeneous } \\
\text { half-space }\end{array}$ & explosion & $60 \mathrm{~m}$ & $\begin{array}{l}\text { effect of topography for half- } \\
\text { space }\end{array}$ \\
\hline 3 & flat & $\begin{array}{l}3 \mathrm{D} \\
\text { homogeneous } \\
\text { layers }\end{array}$ & explosion & $60 \mathrm{~m}$ & $\begin{array}{l}\text { effect of 3D homogeneous } \\
\text { layer structure for flat surface }\end{array}$ \\
\hline 4 & topo & $\begin{array}{l}3 \mathrm{D} \\
\text { homogeneous } \\
\text { layers }\end{array}$ & explosion & $60 \mathrm{~m}$ & $\begin{array}{l}\text { effect of 3D homogeneous } \\
\text { layer structure for topo surface }\end{array}$ \\
\hline
\end{tabular}

Table 2 describes some of the details of the difference between these simulations, including the effects being investigated. In the following we illustrate the effect of 
different model features by showing the full-field images of the ground motions at different times ("snapshots" of the motion) and with the time-domain response at locations of the seismic stations ("synthetic seismograms").

The first comparison shows two cases (Runs 1 and 2 from Table 2) for an explosion at the SPE GZ at $60 \mathrm{~m}$ depth (comparable to the planned 180-190 foot shots for the first two SPE shots). The images in Figure 8 show the vertical component of the ground velocity at 0.75 seconds after the explosion for the flat (left) and topographic (right) cases using a simple half-space model. The response for the flat surface is very simple with just an outward propagating P and Rg wave. The topographic case shows some distortion of the wavefield to the west and north of GZ where topography steepens. This effect is more pronounced at later times when the wavefield passes through the rougher topography to the west and north of GZ.
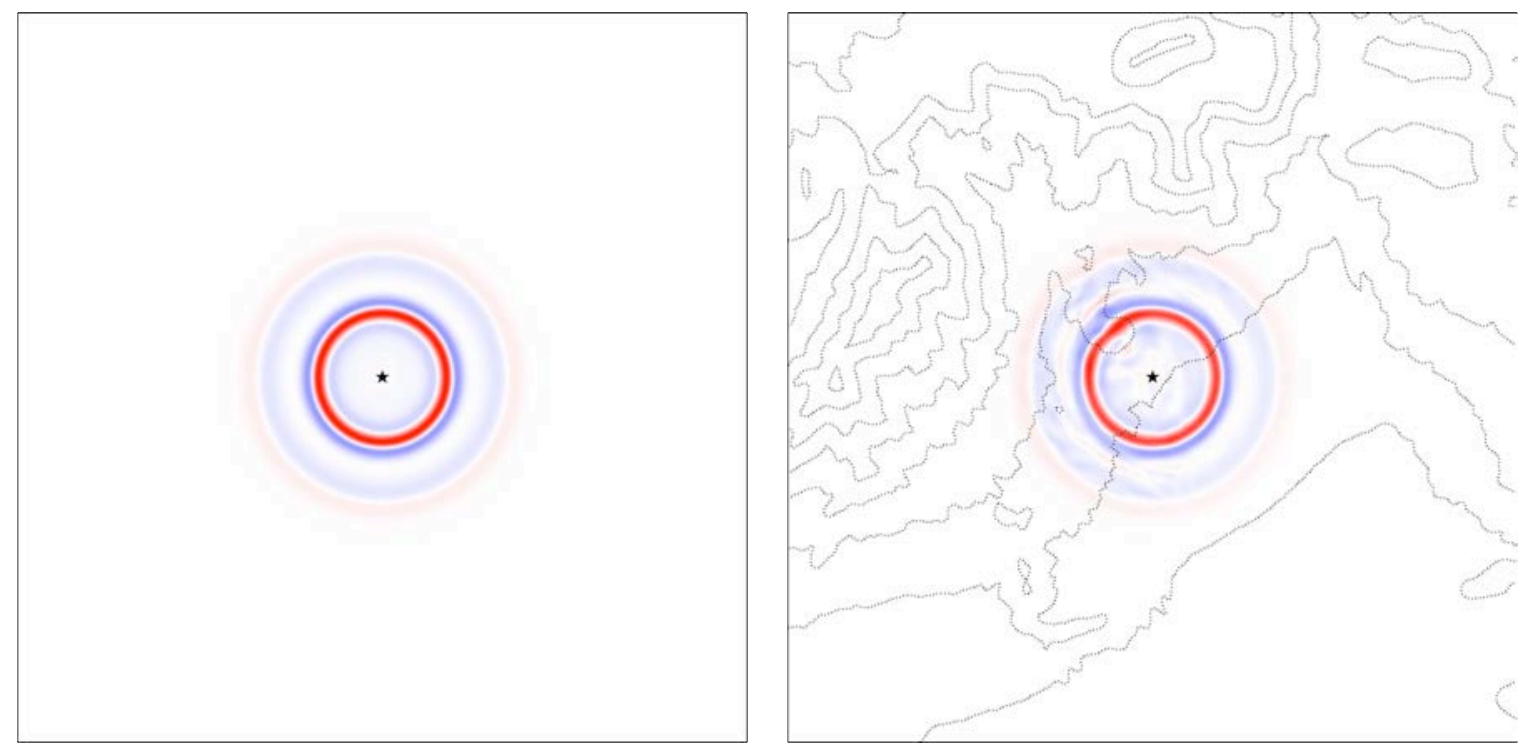

Figure 8. Images of the vertical component of ground velocity at 0.75 second after the shot time for Runs 1 (left) and 2 (right) comparing the response of a granitic half-space model for a flat and topographic free-surface. The topographic contour interval $(100 \mathrm{~m})$ is indicated by the dotted lines. Ground zero (GZ) is indicated by the star.

A similar comparison of the motions is made for cases for flat and topographic free surface with a 3D geologic model (Runs 3 and 4). Figure 9 shows the vertical component 
velocity motions at 0.75 seconds. In this figure the black lines indicate the geologic units at the surface as shown in Figure 5.
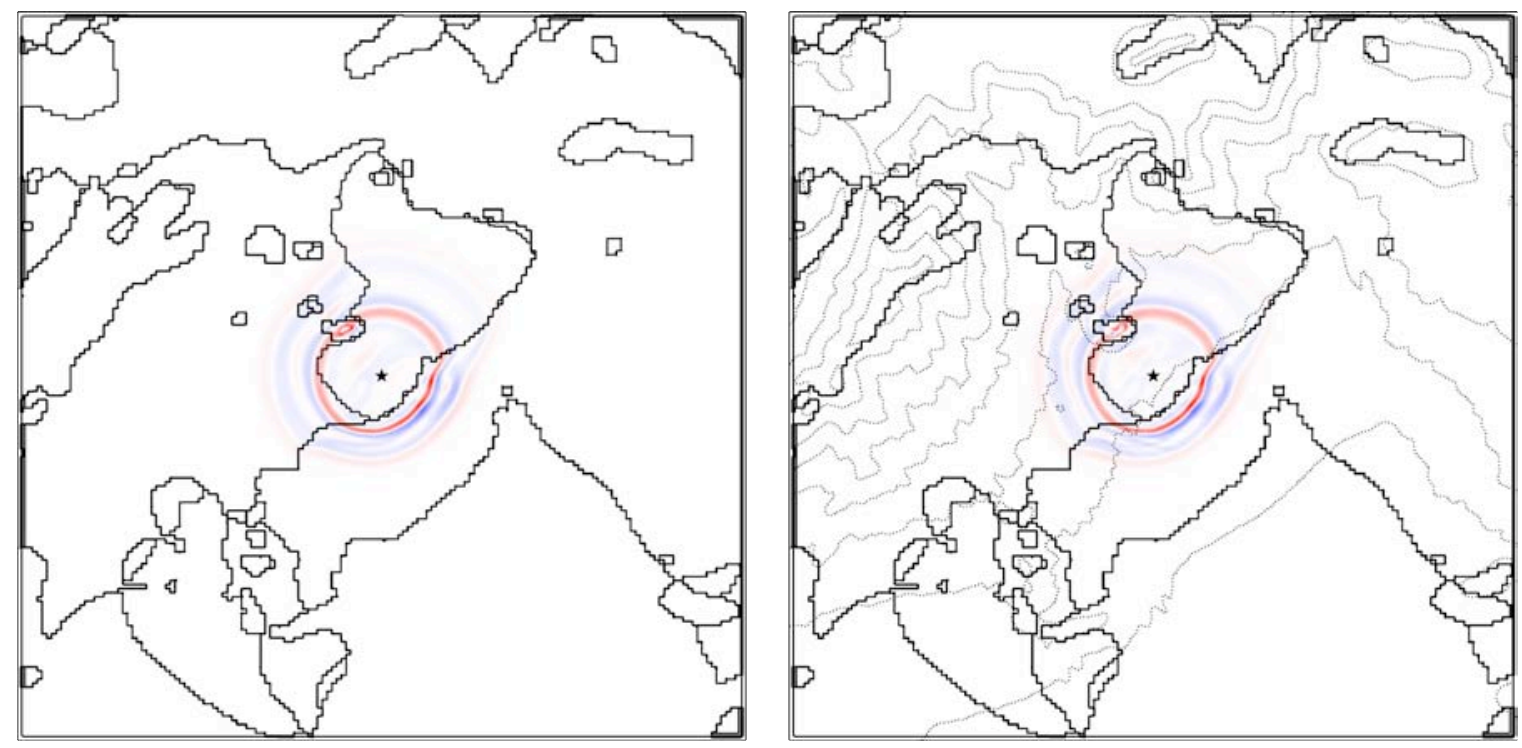

Figure 9. Images of the vertical component of ground velocity at 0.75 second after the shot time for Runs 3 (left) and 4 (right) comparing the response of the 3D geologic model for a flat (left) and topographic (right) free-surface. The boundary between lithologic units and topographic contour interval $(100 \mathrm{~m})$ are indicated by the thick and dotted lines, respectively. Ground zero (GZ) is indicated by the star.

Note in these cases that the geologic structure causes strong distortion of the wavefield compared with the half-space model shown in Figure 8. In particular the passage of the wavefield from the fast granitic lithology of the Climax Stock to the Tertiary tuff lithology to the south and east slows down the waves and shortens the wavelength. The geometry of the contact between the lithologies shapes the wavefield and modifies the amplitudes due to interference effects.

The effects of 3D geologic structure and topography are more pronounced at later times as the waves sample more complexity. Figure 10 shows the vertical component ground velocities for three time steps: 1.0, 1.5 and 2.0 seconds. Notice that the amplification of waves as they pass from the high wavespeed granitic Climax Stock to the lower wavespeed tuff and even lower wavespeed alluvium in Yucca Flat. The wavefronts are strongly distorted by the lateral variations in wavespeed. The small regions of tuff and alluvium lithology to the northwest of the SPE GZ scatter the wavefield. 

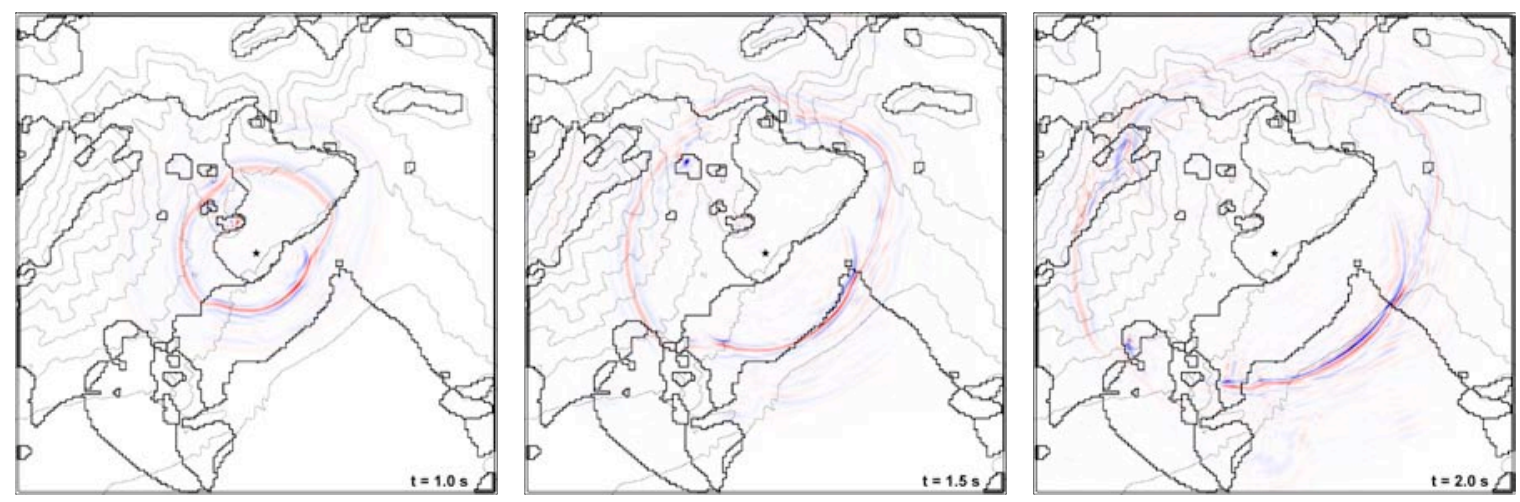

Figure 10. Images of the vertical component ground velocity for Run 4 with the 3D geologic model and surface topography at three time steps: 1.0 (left), 1.5 (center) and 2.0 (right) seconds. The boundary between lithologic units and topographic contour interval $(100 \mathrm{~m})$ are indicated by the thick and dotted lines, respectively. Ground zero (GZ) is indicated by the star.

Dramatic differences in the wavefield are apparent in the time-domain by examining the seismograms for points equidistant from ground zero. Figure 11 shows the synthetic seismograms (ground velocity) along the lines L1-L5 (Figure 4) at stations $1000 \mathrm{~m}$ from ground zero. The responses were decomposed into the vertical, radial and transverse components. The seismograms are plotted with the same amplitude and time scale. It is important to resolve high frequencies close to the source in high wavespeed material such as granite because the wavelengths are larger than in lower wavespeed material. Recall the motions in this report are accurate to slightly over $13 \mathrm{~Hz}$. At $1000 \mathrm{~m}$ the motions have a total duration of less than about 1 second, but at this distance $10 \mathrm{~Hz}$ P- and Swaves in granite have travelled approximately 2 and 3 wavelengths, respectively. For a pure explosion in the half-space model with a flat free-surface (Run 1) the motions are identical at all five locations, the energy is only present on the vertical and radial components and the transverse component has no motion as expected. The half-space model with a topographic free-surface (Run 2) shows a relatively simple response for the vertical and radial components, however the transverse components show some energy, most clearly on line 5, 1 and 2 which samples the rough topography to the northwest of GZ.

The cases with 3D geologic structure (Runs $3 \& 4$ ) show much more complex response at $1000 \mathrm{~m}$ (Figure 11). The paths to the south on lines 3 and 4 show larger amplitudes and 
later arrivals due to slower path-average wavespeeds. These paths also show surprisingly strong amplitudes on the transverse components. The transverse components along lines 3 and 4 show large amplitude arrivals at the time of the Rg wave.
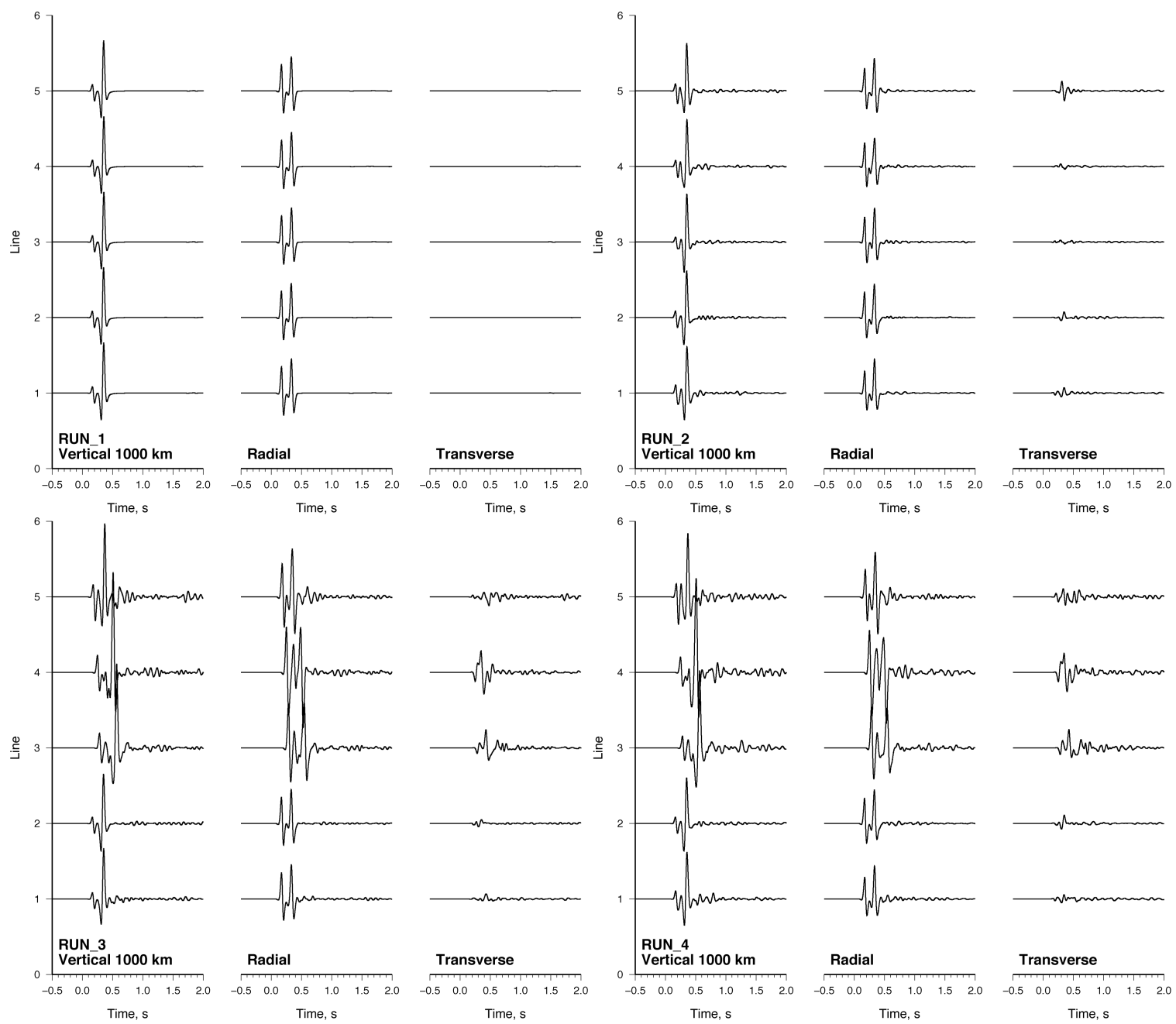

Figure 11. Three-component synthetic seismograms for seismic stations at 1000 from GZ along the seismic lines rotated into vertical, radial and transverse components. Four cases (Runs 1-4) are plotted and the model within the domain (half-space or 3D_geologic) and the topographic conditions (flat or topo) are indicated. All responses are shown with the same amplitude and time scale.

Further complexity in the response is predicted at $2000 \mathrm{~m}$ as shown in Figure 12. The response for Run 1 (half-space model with a flat surface) shows the expected azimuthally independent response and no transverse component energy. The addition of topography for the half-space model (Run 2) shows some scattered energy on the vertical and radial components and energy on the transverse component. The cases with 3D geologic 
structure (Runs $3 \& 4$ ) show more dramatic path effects. The response along lines 3 and 4 show delayed arrivals relative to the other lines. Stations at $2000 \mathrm{~m}$ on lines 3 and 4 are in the alluvium lithology.
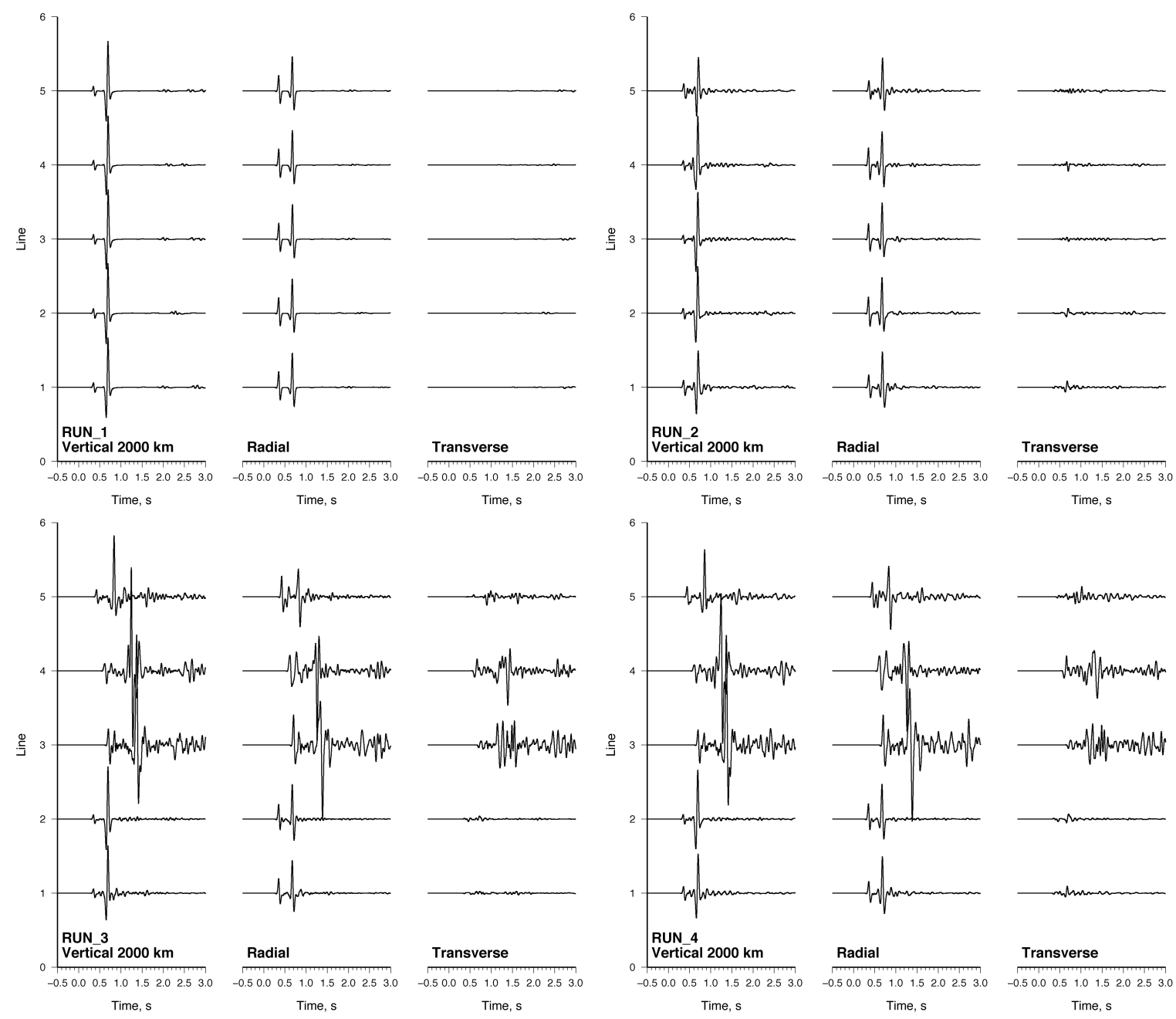

Figure 12. Three-component synthetic seismograms for points 2000 from GZ long the seismic lines rotated into vertical, radial and transverse components. Four cases (Runs 14) are plotted and the model within the domain (half-space or 3D_geologic) and the topographic conditions (flat or topo) are indicated. All responses are shown with the same amplitude and time scale. Note that the time scale is longer than that in Figure 11.

For the 3D geologic model the transverse components are quite large, up to $50 \%$, compared to the vertical and radial. It appears that energy arrives on the transverse component corresponding to $\mathrm{P}$ and $\mathrm{Rg}$ arrivals on the other components. Energy in the coda, which is largest for lines 3 and 4, seems to correlate on all three components with a flat or topographic surface. These observations indicate that $3 \mathrm{D}$ volumetric heterogeneity 
in the near-source region is effective at scattering explosion generated energy from the P$\mathrm{SV}$ system to the $\mathrm{SH}$ system.

\section{Conclusions and Recommendations}

This report describes preliminary efforts to model seismic ground motions for the planned first series of Source Physics Experiments (SPE) at the Nevada National Security Site (NNSS). We built seismic models (densities, compressional and shear wavespeeds) from existing detailed data on lithologic (rock type) layers and average properties of each lithology. A region of $8 \mathrm{~km}$ by $8 \mathrm{~km}$ around the SPE shot was included in our simulation domain and this domain has considerable variation in geologic structure near the surface. Simulations demonstrate that $3 \mathrm{D}$ volumetric structure has a strong impact on ground motions. Topography has a smaller effect on ground motions, however where the topographic is steep the effects are more pronounced. 3D structure has the effect of causing scattering of explosion generated energy, which initiates as purely in the P-SV system (vertical and radial components), to the transverse component. The amplitude of energy on the transverse component is surprisingly large for paths to the south of the SPE ground zero, rising to nearly $50 \%$ of the amplitude on the vertical and radial components.

The large amplitudes on the transverse components for 3D volumetric models indicates that near source geologic structure can be an effective mechanisms for generating shear waves for shallow explosions. Similar results were found for rough topography in a study on the North Korean nuclear test site (Rodgers et al., 2010). If the behavior of our admittedly simple seismic model (constant material properties in laterally varying layers) is representative we expect that shear waves generated by non-linear processes may be difficult to observe once the waves have left the Climax Stock granitic geology. It thus may be worthwhile to deploy additional seismic stations at close range (less than $500 \mathrm{~m}$ ) but at different azimuths.

Further work is needed in several areas. We have generated substantial synthetic data but we have only analyzed a few features of this data set. We would like to make predictions 
of the absolute amplitudes of the SPE shots, based on explosive yields and emplacement conditions. We would also like to investigate the effects of different source mechanisms, including Compensated Linear Vector Dipole (CLVD) sources, within the 3D volumetric and topographic structure of the SPE source region. Finally, we would like to understand how uncertainty in the seismic wave propagation (material) properties of the lithologic layers maps into variations in ground motions.

\section{Acknowledgements}

The numerical methods used in the underlying finite difference approach used by WPP were supported by the Department of Energy Office of Science, Office of Advance Scientific Computing Research. The WPP code was developed in part using LLNL Laboratory Directed Research and Development funding. Simulations were run on the Atlas LINUX cluster operated by Livermore Computing using a $4^{\text {th }}$ Computing Grand Challenge Allocation for which we are grateful. This is LLNL contribution LLNL-TR?????

\section{References}

Aagaard, B., T. Brocher, D. Dreger, A. Frankel, R. Graves, S. Harmsen, S. Larsen, K. McCandless, S. Nilsson, N. A. Petersson, A. Rodgers, B. Sjogreen and M. L. Zoback (2008). Ground motion modeling of the 1906 San Francisco earthquake II: Ground motion estimates for the 1906 earthquake and scenario events, Bull. Seism. Soc. Amer., 98, 1012-1046.

Aagaard, B. T., R. W. Graves, A. Rodgers, T. M. Brocher, R. W. Simpson, D. Dreger, N. A. Petersson, S. C. Larsen and S. Ma (2010). Ground motion modeling of Hayward fault scenario earthquakes II: Simulation of long-period and broadband ground motions, in press at Bull. Seism. Soc. Amer, LLNL-JRNL-419883

Appelo, D. and N.A. Petersson (2008). A stable finite difference method for the elastic wave equation on complex geometries with free surfaces, Comm. Comput. Phys., 5, 84107.

Day, S. M., J. Bielak, D. Dreger, R. Graves, S. Larsen, K. B. Olsen, and A. Pitarka (2001). Tests of 3D elastodynamic codes, Final Report for Lifelines Project 1A02, Pacific Earthquake Engineering Research Center Technical Report, University of California, Berkeley. 
Howard, N. (1985). Variation of properties of nuclear test areas and media at the Nevada Test Site, LLNL Technical Report, UCRL-53721.

Nilsson, S., N.A. Petersson, B. Sjogreen, H.-O. Kreiss (2007). Stable difference approximations for the elastic wave equation in second order formulation, SIAM J. Numer. Anal. 45, 1902-1936.

Petersson, N. A. (2010) https://computation.llnl.gov/casc/serpentine/software.html (website)

Petersson, N.A. and B. Sjögreen (2010a). Stable grid refinement and singular source discretiztion for seismic wave simulations, LLNL-JRNL-419382, Communications in Computational Physics, (2010).

Petersson, N. A., and B. Sjögreen (2010b). Reference guide to WPP version 2.0, Lawrence Livermore National Laboratory technical report, LLNL-TR-422928.

Rodgers, A., A. Petersson, S. Nilsson, B. Sjogreen and K. McCandless (2008). Broadband Waveform Modeling of Moderate Earthquakes in the San Francisco Bay Area to Evaluate the USGS 3D Seismic Velocity Model, Bull. Seism. Soc. Am., 98, 969-988.

Rodgers, A., N. A. Petersson, B. Sjogreen (2010). Simulation of Topographic Effects on Seismic Waves from Shallow Explosions Near the North Korean Nuclear Test Site With Emphasis on Shear Wave Generation, in press Journal Geophysical Research-Solid Earth, doi:10.1029/2010JB007707, LLNL-JRNL-433892. 